\title{
MANUFACTURING OVERVIEW AT THE DEPARTMENT OF ENERGY OAK RIDGE FACILITIES
}

\author{
R. C. Riepe \\ Martin Marietta Energy Systems, Inc. \\ P. O. Box 2009 \\ Oak Ridge, Tennessee 37831-8097
}

\begin{abstract}
Recent changes in the Oak Ridge Y-12 Plant" mission make possible the access by industry to a national resource with a history of manufacturing high precision components from conventional, exotic, and hazardous materials. Turning, milling, grinding, and many nontraditional machining techniques combined with highaccuracy dimensional inspection, nontraditional testing, and a broad range of surface treatments/coatings support national programs requiring the highest possible quality. The Centers for Manufacturing Technology (1-800-356-4USA) at the Oak Ridge Y-12 Plant site provide an impressive mix of resources and opportunities to American industry.
\end{abstract}

\section{Introduction}

The Oak Ridge Y-12 Plant (Y-12) was built by the U.S. Army Corps of Engineers in 1943 as part of the Manhattan Project. Y-12 has developed into a highly sophisticated manufacturing and development organization. This expertise in all aspects of manufacturing technology, when combined with research capabilities available at the Oak Ridge National Laboratory and with Environmental Restoration and Waste Management expertise available at the Oak Ridge K-25 Site, constitutes a formidable resource for the nation's industrial community. Y-12's all-conclusive expertise includes conceptual design, detail design and specification, prototypes, and integrated manufacturing processes.

Y-12 Defense Program assignments include the dismantling of nuclear weapon components returned from the national arsenal, maintaining nuclear production capability and stockpile support, storage of special nuclear materials, and providing special production support to the Department of Energy programs.

The Centers for Manufacturing Technology, located on the Y-12 site, supply skills and facilities developed over the 50-year history of the Oak Ridge Complex to a variety of federal agencies through a Work for Others program. The technology transfer mission has the goal to apply unique expertise to a wide range of manufacturing problems in industry. Manufacturers nationwide can access information and services at Y-12 through a toll-free telephone service (1-800-356-4USA) that is a direct link to experts in this range of manufacturing technologies.

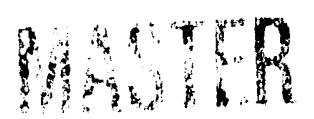

"Managed by Martin Marietta Energy Systems, Inc., for the U.S. Department of Energy under contract DE-ACO5-84OR21400. 


\section{Access}

The Department of Energy (DOE) has recognized the uniqueness of a portion of these facilities and has designated five buildings within the Oak Ridge Centers for Manufacturing Technology (ORCMT) as a User Facility. The DOE User Facility designation provides an easy way to access DOE technology, thereby increasing the dissemination of this federally funded technology into U.S.-based industries. For example, a company (or educational institution) submits a proposal to use these facilities for a specific activity. After the proposal is approved, the company and Martin Marietta Energy Systems, Inc., (MMESI) sign a Standard User Agreement and cooperatively execute the activity.

Presently, the ORCMT User Facility has nine centers, and others are under development. These centers boast an extensive array of equipment, but knowledgeable and experienced personnel are the greatest asset. Available personnel provide a broad expertise for manufacturing research, for application of recently developed manufacturing technology, and for application of best manufacturing practices. The User Facility and the congruent expertise are available to train our customers in the application of modern computer-based manufacturing (modeling, process planning, shop-floor control, etc.). Computer numerically controlled (CNC) technologies and methodologies can be demonstrated, and our customers can learn how to apply these tools.

\section{Ultraprecision Manufacturing Technology Center}

The Ultraprecision Manufacturing Technology Center has been in operation since mid-1989 as a function of the Optics Manufacturing Operations Development and Integrations Laboratory (MODIL).

Five operational cells are available: single-point turning, ductile grinding, ion milling, figure metrology, and finish metrology. The single-point turning and ductile grinding cells incorporate precision zonal temperature control to minimize errors associated with thermal drift. The focus of the center is to develop manufacturing which stress flexibility, versatility, and concurrence throughout the manufacturing cycle.

Participants can conduct high-risk/high-benefit experiments without extensive investment in equipment and instrumentation on the advanced manufacturing and measurement equipment. Through such hands-on experimentation, companies can move new technology quickly into their operations.

\section{Precision Machining and Grinding Center}

The Precision Machining and Grinding Center offers machining and machine tool technologies in private industry, government, and academia. The equipment focus is precision turning and grinding. Special emphasis has been given to deterministic metrology, fixturing, thermal stability, and error correction. The center currently offers two highly enhanced $T$-Base lathes employing state-of-the- 
art fixturing, spindle drives, on-machine probing, tool error correction, etc. A TBase grinding machine for machining ceramics is present. Optical surface inspection and coordinate measuring machine inspection support is available. Extensive intellectual expertise is available to assist with solutions for special problems.

\section{Machine Tool Access Center}

The Machine Tool Access Center (MTAC) is a part of the National Machine Tool Partnership (NMTP). NMTP is a DOE activity in cooperation with the Department of Commerce (DOC) to revitalize the domestic machine tool industry. The Oak Ridge MTAC provides customer services in five strategic areas: information; technical assistance; education and training; benchmarks, demonstrations and evaluations; and standards. Presently, the center includes an Advanced Machine Tool Controller Laboratory and uses the machining resources being deployed in the Precision Machining and Grinding Center.

To receive four workdays of free assistance, call 1-800-35-TOOL-1. Manufacturers can also work with the Machine Tool Partnership through a Cooperative Research and Development Agreement (CRADA) arrangement in which both partners (DOE and the manufacturer) contribute half of the expertise and cost of the project.

\section{The Metrology Center}

The Metrology Center serves to develop, advance, and implement measurement technologies. Equipment and expertise have evolved to meet a continuing challenge for state-of-the-art measurement accuracy. Focus areas in the center are as follows: Gage Laboratory, Dimensional Inspection, Physical and Electrical Standards Laboratory, Gear Metrology, and Accreditation Initiatives. The center has a successful track record of calibrations that are directly traceable to the National Institute of Standards and Technology (NIST). The center and NIST are presently developing criteria for the NIST National Voluntary Laboratory Accreditation Program (NVLAP).

\section{Concurrent Engineering Center}

A Concurrent Engineering Center is established in the User Facility by bringing together Y-12's extensive computer-integrated enterprise technologies. Twelve technologies will be interconnected to demonstrate a seamless flow of manufacturing information including product modeling, visualization/simulation, engineering analysis, data translation, neı ork administration, computer-aided manufacturing (CAD) for fabrication, $\mathrm{CAL}$ ) for certification, metrology, rapid response manufacturing (RRM), Direct Numerical Control (DNC), process planning, and shop-floor control. These technologies will be deployed for largescale enterprises and on personal computer/workstation environments more suitable for small-scale manufacturing applications. 


\section{Skills Development Center}

The focus of this center is to assist in the evaluation, development, selection, and implementation of fabrication technologies that improve the competitiveness of small- to medium-sized companies engaged in the manufacturing of metal, ceramic, plastic, and composite parts, assemblies, and/or components surfaceenhanced by coatings. The center provides the tools and operational skills for validating and demonstrating in real time a pilot or prototype facility. The eight demonstrations areas in this center focus on CNC turning, $\mathrm{CNC}$ milling, electric discharge machining, machine tool evaluation, multi-axis pulsed metal arc welding, laser welding, gas tungsten arc adaptive welding, and superplastic forming.

\section{Manufacturing Analysis Center}

The Manufacturing Analysis Center offers extensive evaluation and analysis technologies for support of manufacturing processes. The technologies available in the center include surface characterization, materials analysis, nondestructive testing, environmental monitoring, manufacturing modeling, and information/advisory systems. The center offers the following resources for evaluation of customer materials and process output: an extensive array of materials/surface science instruments; a wide variety of inspection equipment for nondestructive evaluation of items that require verification of "fitness for intended use"; and environmental sensor laboratory for field instrumentation used to monitor heavy metals and organics at regulatory levels. An information/advisory system test bed facilitates development in information management, geographic information, intelligent systems/advisors, data analysis, visualization, and information presentation. A networking center facilitates process simulation characterization modeling. This includes evaluation of Neural networks, Artificial Intelligence Systems, Fuzzy Logic methodologies, etc .

\section{Advanced Coatings Manufacturing Technology Center}

The center is designed to develop and demonstrate solutions to the critical issues surrounding materials deposition, and coating manufacturing. The center will provide the manufacturing process testbeds to validate integrated coating processes for emerging coating materials while using manufacturing prototype cells. The center offers coating processes for plasma spray (PS) and physical vapor disposition (PVD). Systems for robotic PS, powerturn lathe PS, glove box hand-operated PS, and a glove box manipulator-controlled PS are currently installed in the center. Robotic closed-looped controlled PS; flame spray; highvelocity oxy-fuel (HVOF); low-pressure PS; in-process control vision particle tracker; environmental chamber for lathe PS; grit blasting; hardness tester; closed-circuit camera control; diamond saw; and (of primary importance) ventilation (bag houses) are planned. A Balzers Magnetron sputter deposition system [1-m(3)] with reactive capability and a small magnetron sputter deposition system are available. 


\section{Unusual Capabilities}

Foundry capabilities exist for a variety of metals and alloys, including those that are radioactive, pyrophoric, and/or hazardous. Components can be cast shapes at near-machining size or billets and ingots, which may receive subsequent metalworking operations. Power metallurgy and ceramic compaction, outgassing, and sintering are performed on a variety of materials. Isostatic presses with chambers up to 60 in. diameter and $60 \mathrm{in}$. deep may be operated from room temperature up to $150^{\circ} \mathrm{C}$. Vacuum induction melting furnaces are available in a wide range of sizes. Crucibles from 13 to 30 in. diameter can be accommodated, and temperatures of up to $1950^{\circ} \mathrm{C}$ can be reached with vacuum capabilities. Some furnaces have been modified to allow introduction of gases for improved compositional control. Design and production of customized molds for casting operations are performed to meet unique requirements of individual jobs. Vacuum arc melting is also performed when refinement of material composition is required for metals having a very high melting point. The process may also be used to create unique, high-purity alloys, particularly when materials tend not to alloy easily. State-of-the-art computer controls optimize the quality of vacuum arc-melted material produced. Sizes of up to 10 in. diameter can be supported.

Metalworking by rolling, forging, forming, cleaning, and heat-treating can be done on a wide variety of hazardous and nonhazardous metals. Development and modification of manufacturing processes, equipment, and tooling is performed to meet unique customer requirements. Engineering support is also provided for waste minimization and environmental initiatives; for example, aqueous ultrasonic detergent cleaning methods for degreasing and cleaning have replaced chlorinated solvents and acids as environmentally acceptable substitutes.

Rolling mills are available to support a wide range of component sizes. The largest one, a 66 in. wide, four-high reversing rolling mill, can break down billets up to $11 \mathrm{in}$. thick into 0.25 in. thick plates. Another mill can roll 40 in. wide precision sheets from 0.25 to 0.005 in. thickness with very close tolerances.

Heat treating is performed by a variety of air, vacuum, and inert atmosphere furnaces. The largest inert atmosphere furnace can accommodate charges of $3000 \mathrm{lb}$; vacuum furnaces reach temperatures of $1800^{\circ} \mathrm{C}$. Customized facilities enable immediate quenching if required.

Large, triple-action presses are available for forging and deep-draw forming with tonnages up to 7500 tons. Pressing capability exists for ceramic/metallurgical (cermet) components that require powder compaction technology. Precision hydroforming machines can accommodate parts from 2 to 30 in. diameter with up to 0.625 in. thickness. Cold and warm forming is supported with maximum pressures of 23,500 psi and 15 in. draw depth. Argon atmosphere forming units are available for controlled gas blow-forming of superplastic materials.

Precision machining capability includes turning, milling, and grinding of a 
multitude of standard and exotic materials. Nontraditional machining processes, such as diamond turning, electrical-discharge machining, and ceramics grinding, are supported as well. Multiaxis mills are used to meet fabrication requirements created by intricate part designs of complex geometric shapes. A distributed numerical control system links computer-aided design systems and numerical control generation software directly to the machine in a paperless environment.

Resources are available for manufacturing high-quality ceramics structures. Proven manufacturing processes are (1) quasi-isostatic hot pressing incorporating large hydraulic presses in induction furnaces with natural flake graphite as the pressure transmitting media, and (2) hot isostatic pressing using vessels with parametric ranges to $30,000 \mathrm{psi}$ and $1700^{\circ} \mathrm{C}$. The potential of microwave sintering for ceramics manufacturing is an active development area. The 60 in. diameter by $60 \mathrm{in}$. deep working chamber of the oil-isostatic press is one of the largest 30,000 psi presses in the world, with a vessel end loading of 45,000 tons. The press, which can be operated as hot as $150^{\circ} \mathrm{C}$, is used to compact elastomeric molds that contain ceramic powders. The powder is formed into a dense ceramic shape. The outgassing furnaces are capable of being loaded from an inert atmosphere and sealed. The ceramic parts are heated with controlledtemperature rates up to a maximum of $600^{\circ} \mathrm{C}$ under vacuum.

Capabilities exist for welding and assembling a wide range of materials to exacting customer specifications. To minimize environmental variations, low humidity (10\% or less) is constantly maintained and monitored in the assembly area. Parts weighing up to five tons can be processed with dimensions of up to $8 \mathrm{ft}$ wide and $10 \mathrm{ft}$ high. A unique, controlled-environment room is available for operations which require a moisture level of $30 \mathrm{ppm}$ or less. Extensive nondestructive testing capabilities are available for assembly quality evaluation.

Both traditional and advanced joining techniques are performed, such as gas tungsten arc welding, gas metal arc welding, shielded metal arc welding, plasma arc welding, vacuum furnace brazing, laser beam welding, friction welding, and electron beam welding. Helium and argon leak-test equipment can certify weld quality to $1 \times 10^{-8} \mathrm{~cm}^{3} / \mathrm{s}$. Welding procedures can be qualified to Military Standards or the ASME Boiler Code. Development activities include implementation of adaptive control systems and inertia friction welding of refractory metals. Customer performance requirements are often met through the development and formulation of special adhesive systems and curing agents. Unique applications include high-performance materials with low-temperature cure cycles; bonding of dissimilar exotic materials, microapplication techniques; vacuum backfill; potting for continuous, void-free, bond lines; and continuous submersion adhesives for various liquid environments. 
Distribution:

Oak Ridge National Laboratory

F. G. Pin

R. M. Schilling

Oak Ridge Y-12 Plant

V. B. Campbell

A. K. Lee/DOE-OSTI (2)

W. G. Northcutt, Jr.

R. C. Riepe

Y-12 Central Files - RC 


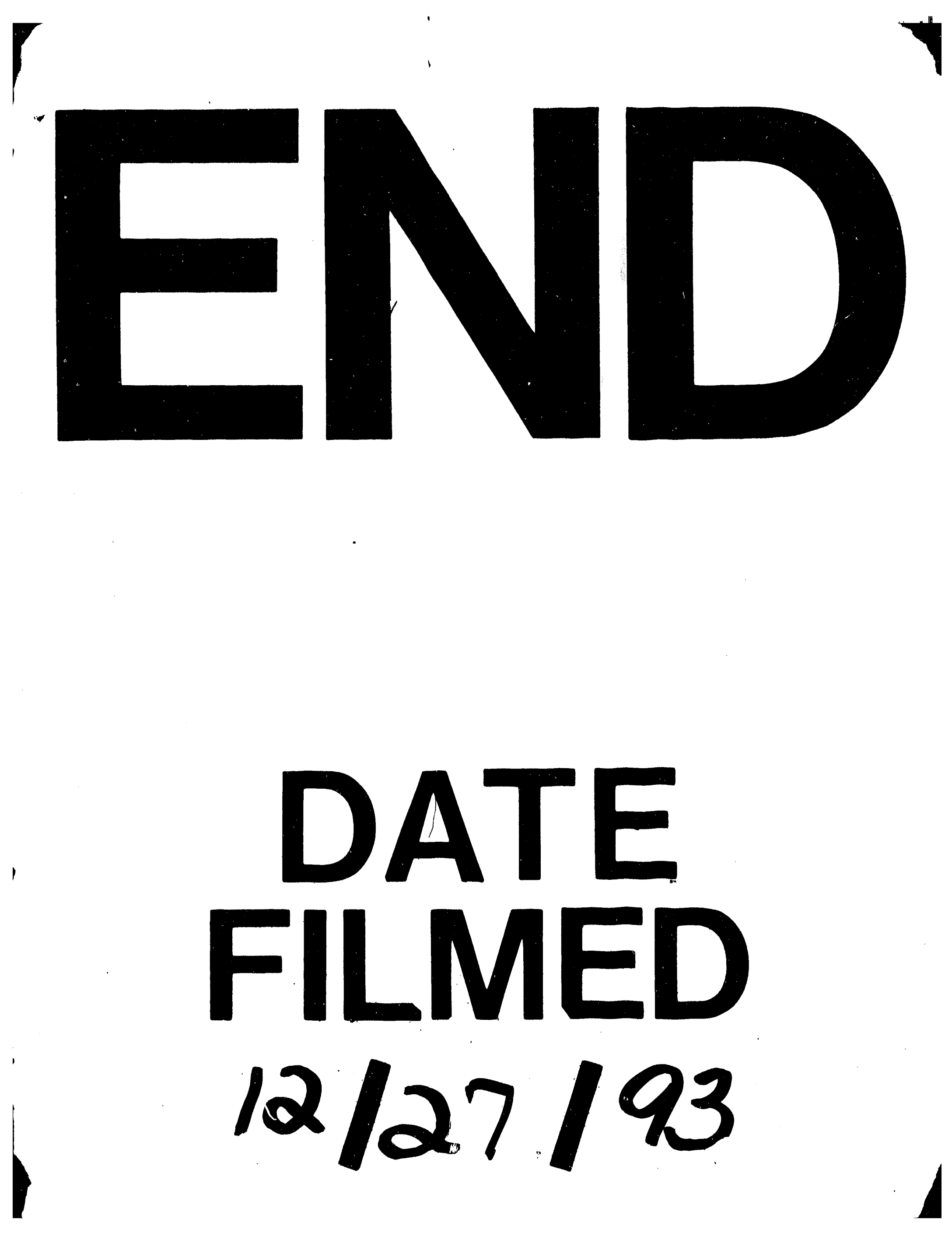


